\title{
STIGMA RECEPTIVITY AND POLLEN VIABILITY OF Melaleuca alternifolia
}

\author{
Liliana Baskorowati ${ }^{1}$
}

\begin{abstract}
Stigma receptivity based on seed set and pollen tubes growth following controlled pollination of flowers of different ages was examined in Melaleuca alternifolia. The stigma secretion during 10 days after anthesis and pollen viability under three different temperatures and five storage times were also observed. These series of research were undertaken because successful controlled pollination of $M$. alternifolia depends on the application of viable pollen to the receptive compatible stigma. The objective of this research was therefore to determine the stigma receptivity and pollen viability of $M$. alternifolia. Results showed that the stigma receptivity began to develop on day one and finished on day seven after anthesis, peak receptivity occurred from day three to day six. The stigma receptivity also coincides with the appearance of secretion in the stigma, occurring from day three to day seven after anthesis. Therefore, the time for pollination of $M$. alternifolia appeared to extend for approximately 7 days after anthesis. Data for $M$. alternifolia showed that regardless of storage temperature, pollen was still viable after 26 weeks of storage; results also demonstrated that the lowest temperature $\left(-18^{\circ} \mathrm{C}\right)$ was the best regime for long term storage.
\end{abstract}

Keywords: Pollen tubes growth, seed set, pollen storage

\section{INTRODUCTION}

Melaleuca alternifolia is native to Australia and cultivated to produce essential oil known as tea tree oil. Tea tree oil is rich of terpinen-4-ol distilled from the leaf of $M$. alternifolia. Breeding strategy to improve the quality and quantity of tea tree oil has been established since 1993. Controlled pollination among selected families is an important element of this strategy. Therefore, understanding on fundamental aspects of reproductive biology of the species such as stigma receptivity and pollen viability is essential to ensure successful controlled pollination.

A stigma is receptive when it has the ability to support pollen germination and the onset of stigmatic receptivity is accompanied by a number of changes occurring upon maturation of the stigma (Sanzol and Herrero, 2001). Sticky secretion usually accompanying the female stage of the flower that indicates receptivity (HeslopHarrison and Shivanna, 1977). Sedgley and Smith (1989) found that both stigma secretion and ability to support pollen germination and tube growth increased with time, reaching a peak at 7 days after anthesis in Eucalyptus woodwardii.

1 Center for Forest Biotechnology and Tree Improvement Research, Jl. Palagan Tentara Pelajar Km. 15, Purwobinangun, Pakem, Sleman, Yogyakarta, Indonesia. E-mail: lbaskorowati@yahoo.com. 
Stigma receptivity can be determined by examining characteristics such as (a) the number of fruit and seed set following compatible pollination (Holmes, 2000); (b) the length of compatible pollen tubes growing down the stigma (Oddie and McComb, 1998); and (c) peroxidise activity of the stigma at different times after anthesis (Holmes, 2000). In this observation, the first two of these methods were used to determine the period of stigma receptivity. Microscopic observation using a Scanning Electron Microscope (SEM) was also used for stigma secretion observation.

An efficient pollen management system that includes collection, storage and testing methods is required to produce high quality pollen for controlled pollination and thus for controlled pollinated seed production (Griffin et al., 1982). Published reports of procedures for handling and storage of eucalypt pollen include those of Pryor (1976) and van Wyk (1977). Boden (1958) reported that the pollen of various Eucalyptus species retains its viability for up to 12 months after collection, when collected at anthesis and stored in a deep freeze at $-16^{\circ} \mathrm{C}$. Similarly, Griffin et al. (1982) in a study of E. regnans, reported high pollen viability after 12 month's storage at $-16^{\circ} \mathrm{C}$. However, at room temperature, pollen of this species retained viability for only 36 days.

There is limited published information about pollen viability in Melaleuca and its longevity under different storage conditions. A report on viability of $M$. cajuputi subsp. cajuputi pollen using agar medium showed that pollen was highly viable $(66 \%)$ soon after collection, dropped to $35 \%$ viability after 3 months of storage in an air tight bottle in the refrigerator $\left(3-5^{\circ} \mathrm{C}\right)$, but this had decreased to $4 \%$ viability after 4.5 months of storage (Hendrati et al., 2002).

Study of stigma receptivity and pollen viability support the successful controlled pollination of $M$. alternifolia, since the application of viable pollen on the receptive stigma will increase the number of seed set. Therefore, the aims of the present study were to determine the time of stigma receptivity and pollen viability of $M$. alternifolia.

\section{MATERIALS AND METHODS}

\section{A. Materials}

Field observations were conducted at M. alternifolia seedling seed orchard second generation at West Wyalong, NSW, Australia, and in ANU glass house, Canberra. One family 17 was used for stigma receptivity based on seed set observation. While three ramets of clone C2 (provenance Candole) growing in an ANU glasshouse were used for stigma receptivity observation based on microscopic observation and pollen tubes growth. Pollen samples for pollen viability assessment were collected from four sample trees located in commercial plantations at West Wyalong, NSW, 
Australia. Laboratory observations were undertaken at Electron Microscopy Unit (EMU) laboratory ANU, Canberra, Australia.

\section{B. Methods}

1. Stigma receptivity based on microscopic observation and pollen tube growth

Three ramets of clone C2 which had abundant flowers growing in an ANU glasshouse were chosen for stigma receptivity observation on the basis of pollen tube development. On each of the three trees, a minimum of 11 inflorescences at the same stage of flower development (1 day before anthesis) were emasculated and isolated using a pollination bag. The emasculated flowers were pollinated at various times (anthesis, day 1, 2, 3, 4, 5, 6, 7, 8, 9, 10 following anthesis). Techniques for emasculation and pollination followed the methods as described by Baskorowati (2006).

The pollinated stigmas were then harvested 5 days after pollination for fluorescence microscope and SEM observations. For fluorescence observation sample was placed in Carnoy's fixative $(6: 3: 1$ absolute ethanol : chloroform : glacial acetic acid) for at least 24 hours, and the fixed material was then dehydrated through an alcohol series $(90 \%, 70 \%$ and $30 \%)$. The stigmas were then softened in $0.1 \mathrm{~N}$ sodium hydroxide at $60^{\circ} \mathrm{C}$ for a minimum of 5 hours, stained with decolorized aniline blue overnight (Martin, 1959), and prepared for observation under a microscope. For observation under SEM, pistils were put in the petridish containing wet Whatman paper. Samples for SEM were prepared following a cryo-SEM method of Craig and Beaton (1996).

2. Stigma receptivity based on seed set

On every sample tree, a minimum of 50 inflorescences bearing in aggregate at least 450 flowers were emasculated and isolated by covering the flowers using pollination bags (type PBS 10-1, size 255 x $510 \mathrm{~mm}$, manufactured from non-woven polyester by PBS International Plant Breeding Supplies, UK). The emasculated flowers were then pollinated at various times (day 1, 2, 3, 4, 5, 6 and 7) following anthesis. Pollen for pollinating the stigma were used stored pollen with the pollen viability $76 \%$. Conventional controlled pollination methods (Baskorowati, 2006) were used for pollen delivery. The numbers of capsules set were counted and capsules were harvested in March 2007, at 16 months after pollination.

\section{Pollen viability}

Methods for pollen collection were used as described by Baskorowati (2006). Methods for extraction in this study were modified from those used for extraction of pollen of Acacia species (Sedgley et al., 1992). Dried flowers from each sample were placed into a $50 \mathrm{~mm}$ sieve and crushed using a paint brush to remove the larger debris. The pollen in the mixture with the small debris was sieved through a 
$53 \mathrm{~mm}$ sieve to clean the pollen. A black glass surface was placed below the $53 \mathrm{~mm}$ sieve so that clean pollen, which is creamy yellow in color, could be easily seen. Pollen was picked up with a toothpick and placed into small sterile airtight vials and clearly labelled. All the tools and the desk were sterilized using $100 \%$ ethanol before extracting another sample, to avoid contamination. Dried pollen was then tested for moisture content using the low constant temperature oven method (Gunn, 2001).

Pollen samples in tightly sealed glass vials were stored at each of the following temperatures: at room temperature $\left(21-24^{\circ} \mathrm{C}\right)$, in a refrigerator $\left(3-5^{\circ} \mathrm{C}\right)$; and in a deep freezer $\left(-18^{\circ} \mathrm{C}\right)$. Pollen was tested for germination after being stored for 1,14 , 26, 38 and 52 weeks. Twenty vials each containing small amounts of pollen were placed into the three different temperature storages; four vials were taken from each storage regime at each allotted time for pollen germination testing.

Pollen viability was tested using liquid medium in-vitro techniques (Griffin et al., 1982). Pollen was incubated at $25^{\circ} \mathrm{C}$ in a solution of $30 \%$ sucrose to which was added $150 \mathrm{ppm}$ of boric acid. Approximately $0.2 \mathrm{ml}$ of the solution was transferred into a vial, and then a small amount of pollen, picked up using a toothpick, was added to the vial. The vials were shaken, labelled and incubated at $25^{\circ} \mathrm{C}$. Germination was recorded after 24 hours by counting the pollen grains under a microscope at $40 \mathrm{X}$ magnification. The grain is considered germinated if the pollen tube is twice the diameter of the pollen (Owens et al., 1992).

\section{Statistical Analysis}

Wald test with REML methods were used to test the significant effects of treatments. For observation of stigma receptivity based on pollen tubes growth the number of pollen grain was used as response-variate and the time of pollination as fixed effect. For pollen viability observation, the germination rate was used as response-variate with time interval and storage time as fixed effects.

The model was: $Y_{\mathrm{ij}}=\mu+r_{\mathrm{i}}+t_{\mathrm{j}}+e_{\mathrm{ij}}$

$Y_{\mathrm{ij}}=$ observation

$\mu=$ overall mean

$r_{i}=$ replicate effect

$t_{i}=$ treatment effect

$e_{\mathrm{ij}}=$ residual

\section{RESULTS AND DISCUSSION}

\section{A. Stigma Receptivity}

Based on microscopic observation, the mean number of days for stigma secretion is $2.2 \pm 0.48(\mathrm{n}=5)$ days from anthesis. Scanning electron micrographs (Figure 1) show that the exudates on the top of the stigma become obvious by the 
third day following anthesis (Figure 1. D) and all of the stigma is covered by the secretion by the fourth day (Figure 1. E). However, the secretion still appears on styles 10 days after anthesis, despite the fact that the secretion starts to dry by day 5 (Figure 1. F).

This study found M. alternifolia to have, in terms of the classification by HeslopHarrison and Shivanna (1977), a wet papillate stigma. The SEM study showed that stigmas were dry at anthesis, but had copious secretions commencing 2 to 3 days post-anthesis (Figure 1) and thereafter for a period of 3 days. The stigmatic region increased in area to $650 \mathrm{~mm}$ following the first secretion, which was yellow, shiny and sticky. Similar associations between changes in stigma appearance and peak stigma receptivity have been observed in other Melaleuca (Hendrati et al., 2002) and Eucalyptus species (Hodgson, 1976; Griffin and Hand, 1979; Cauvin, 1984; Tibbits, 1989; Savva et al., 1988; Sedgley and Smith, 1989; Oddie and McComb, 1998).

The number of pollen tubes found in the style differs significantly between pollination dates (REML analysis; Wald stat $=377.4$, d.f. $=10, \mathrm{c}=<0.001$ ). The differences demonstrated that the number of pollen tubes observed relates to the maturity of the stigma. Figure 2 illustrates that the number of pollen tubes in the style increased from anthesis to 4 days after anthesis, and drastically decreased by day 7. The stigmas are receptive during days 1 to 6 with peak receptivity during day 3 to 6. Small numbers of pollen tubes were observed at anthesis and on days 7 to 10 after anthesis, suggesting that pollination may still occur during these times, as shown in Figure 2. Results of stigma receptivity assessment based on the number of pollen tubes confirm the progressive nature of stigmatic receptivity in M. alternifolia (Figure 2). They also indicated that the maximum stigma receptivity is 3 to 6 days after anthesis, with peak receptivity 4 days after anthesis, thus confirming the results of assessment of stigma maturity based on seed set (Figure 3).

Stigma receptivity is associated with morphological changes to the stigma as shown in Figure 1. Enlargement of the stigma and the wet sticky appearance of the surface due to exudates indicate that the stigma is receptive. The percentage of mature capsules on sample tree following pollination on days 1 to 7 after anthesis is shown in Figure 3.

Capsules were formed following hand pollinations conducted 1 to 7 days after anthesis. The stigma is most receptive during days 2 to 4 following anthesis based on capsules formed. The stigma is, however, still receptive during the period 1 to 7 days after anthesis and capable of being fertilized. 


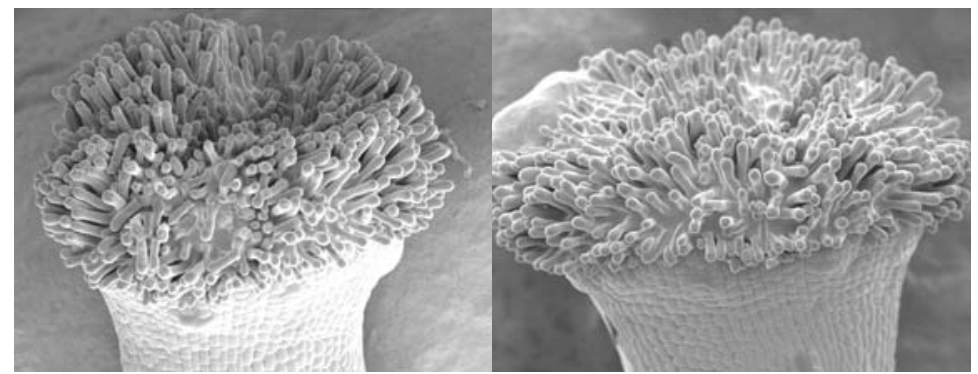

A - anthesis

B - 1 day after anthesis

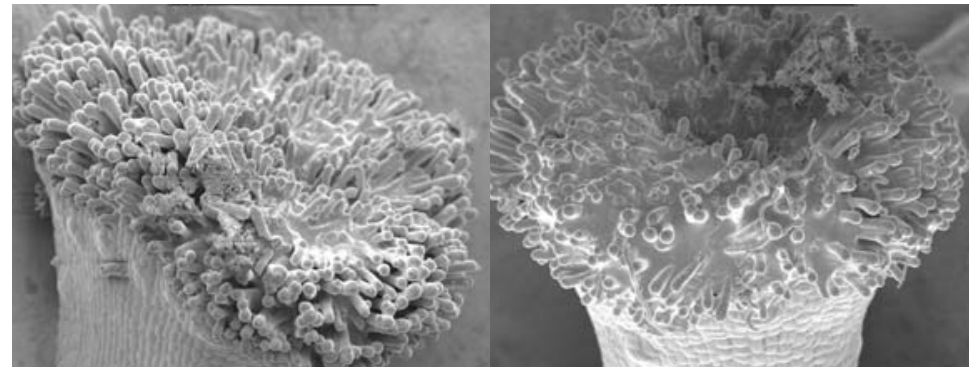

C - 2 days after anthesis

D - 3 days after anthesis

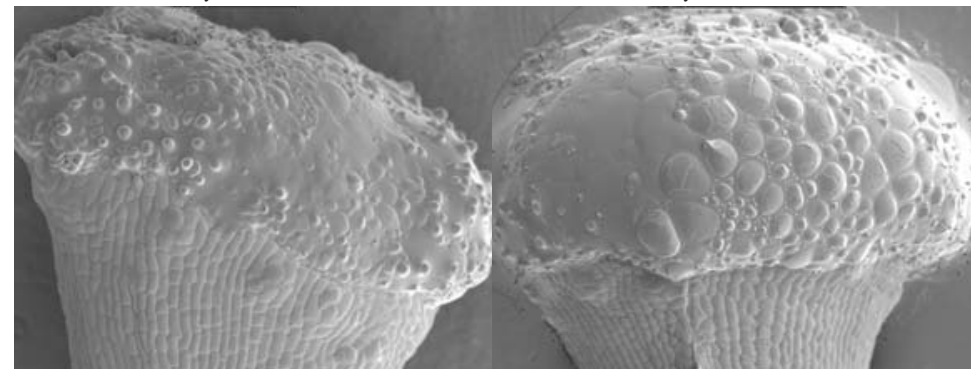

E - 4 days after anthesis

F - 5 days after anthesis

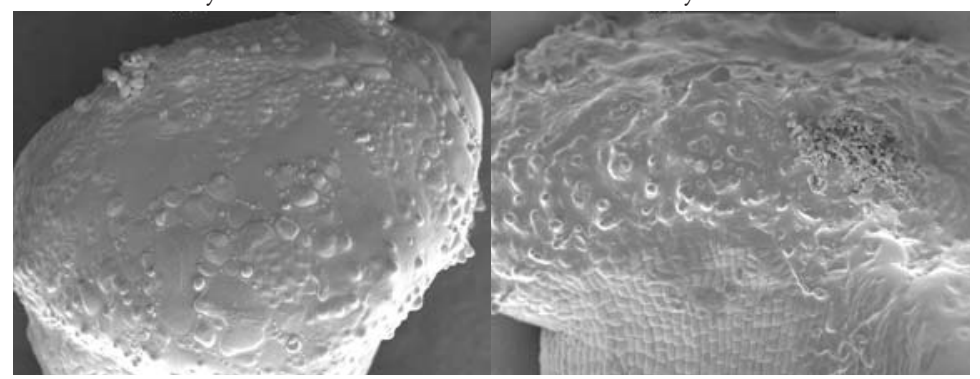

G - 7days after anthesis

H - 10 days after anthesis

Figure 1. Scanning electron microscope images of stigma at anthesis, 1-, 2-, 3-, 4-, 5-, 7- and 10- days after anthesis; bar $=200 \mu \mathrm{m}$ 


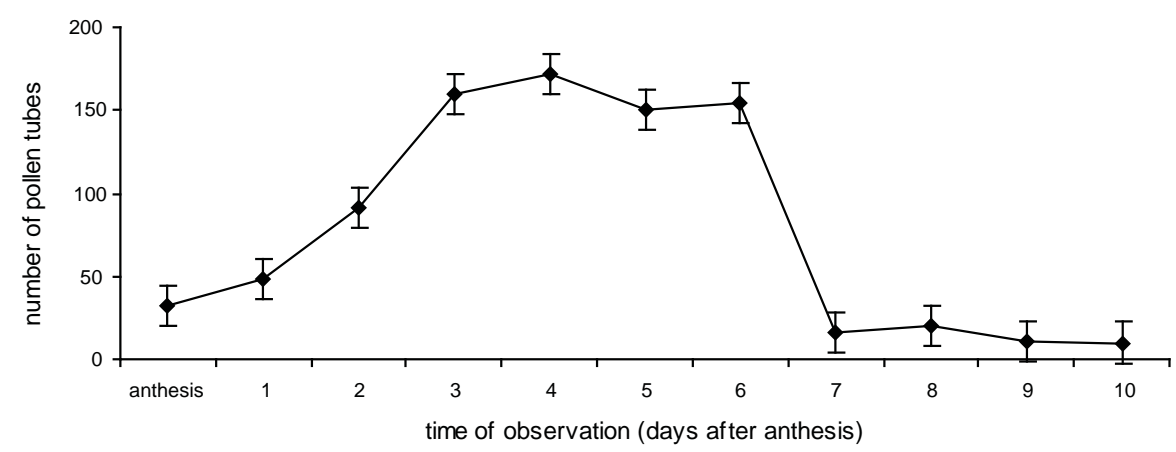

Figure 2. Mean number of pollen tubes recorded in the style of three glasshouse-grown plants following hand pollination conducted from anthesis to 10 days after anthesis, with associated standard errors

Data on capsule set from pollination day 3 were not available due to the branch being broken. Data from inspection records of this branch showed that $92.3 \%$ of healthy capsules were retained up to this stage. This suggests that stigma receptivity peaks on days 2, 3 and 4 after anthesis.

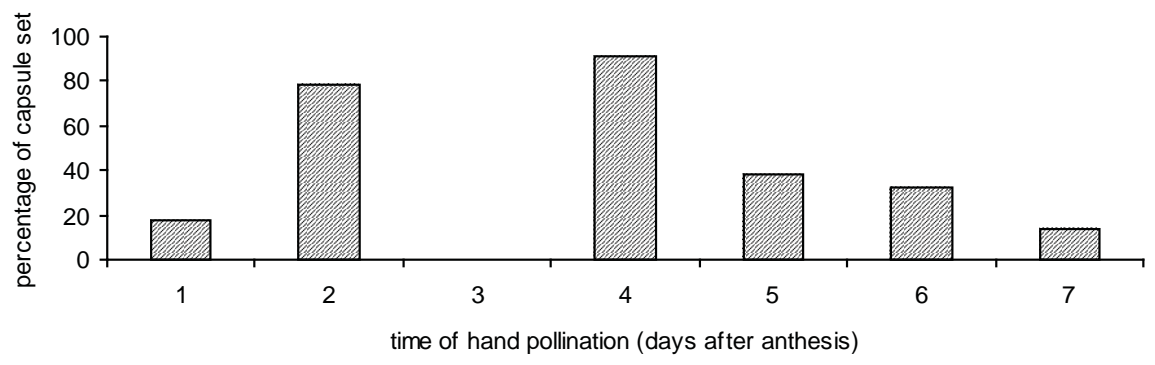

Figure 3. Percentage of capsules set on three field-grown plants (seed orchard at West Wyalong, NSW) following hand pollination conducted from 1 to 7 days after anthesis. Note: data not available for day 3 due to broken branch

The results of stigma receptivity based on the success of seed set (Figure 2) indicated that stigma receptivity began to develop 1 day after-anthesis, but the highest germination rates on stigmas were observed 3-4 days after-anthesis, and individual stigmas remained receptive for 7 days after-anthesis. This indicates that, in M. alternifolia, the development of stigmatic receptivity is progressive. This progressive receptivity of the stigma has also been reported in other Myrtaceous species (Griffin and Hand, 1979; Sedgley and Smith, 1989; O’Brien, 1996; Page et al., 2006). 


\section{B. Pollen Viability}

The pollen viability of $M$. alternifolia varied significantly with time of storage (REML analysis; Wald stat $=112.9$, d.f. $=4, \mathrm{c}=<0.001)$ and temperature of storage (Wald stat $=23.9$, d.f. $=2, \mathrm{c}=<0.001$ ). In addition, the interaction of temperature and storage time was significant (Wald stat $=16.19$, d.f. $=8, \mathrm{c}=$ 0.04). Pollen of $M$. alternifolia was still viable after 52 weeks of storage under all temperature regimes, with storage in the deep freezer $\left(-18^{\circ} \mathrm{C}\right)$ providing the best results (Figure 4).

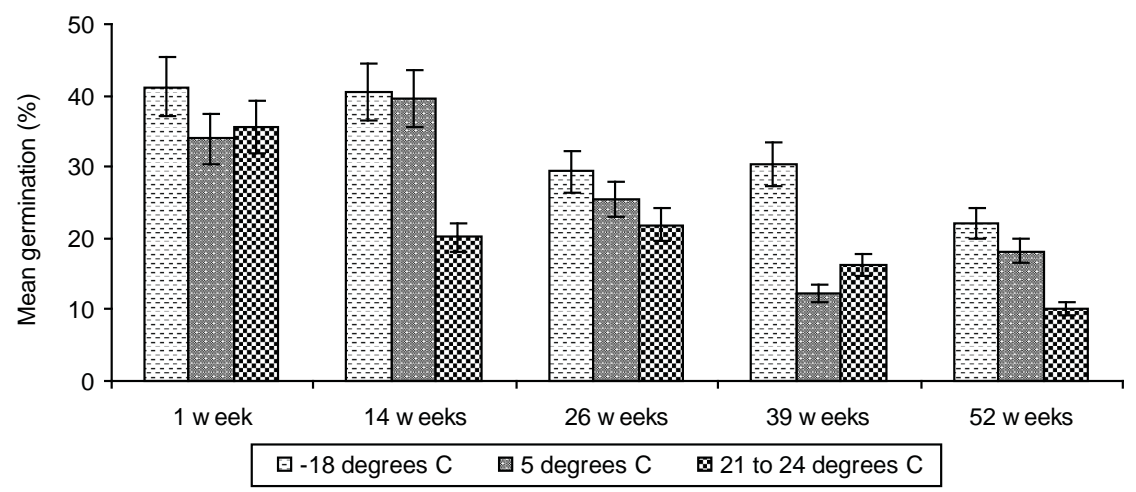

Figure 4. Pollen viability of $M$. alternifolia following storage for different durations and temperatures, and associated standard errors

The results of pollen storage trials for $M$. alternifolia conducted here are consistent with results of other species. Generally, pollen viability of angiosperms declines with the period of storage time, most markedly with higher temperatures and relative humidities (Jain and Shivana, 1989). Several studies of Australian genera suggest that storage at low temperature is the best way to maintain viability. Eucalyptus pollen has successfully maintained its germination percentage when stored at $-16^{\circ} \mathrm{C}$ to $-20^{\circ} \mathrm{C}$ or $-80^{\circ} \mathrm{C}$ for periods of up to three years (in $E$. maculosaBoden, 1958; E. regnans-Griffin et al., 1982; E. globulus, E. urnigera, E. morrisbyiPotts and Marsden-Smedley, 1989; E. smithii, E. nitens and E. grandis-Horsley et al., 2007). Low temperature $\left(-18^{\circ} \mathrm{C}\right)$ was also noted as the most successful storage condition for Australian species of Acacia (Sedgley and Harbard, 1993). However, storage of eucalypt pollen at room temperature or at $4^{\circ} \mathrm{C}$ is still acceptable if the pollen will be utilized within 1 to 2 months (Griffin et al., 1982; Horsley et al., 2007). Similar results have been found for pollen of $M$. cajuputi subsp cajuputi, which maintains its viability up to $30 \%$ when stored in the refrigerator for 3 months (Hendrati et al., 2002). 
The loss of pollen viability generally is affected by environmental conditions, particularly by temperature and relative humidity (Jain and Shivana, 1989). Pollen reserved at room temperature usually deteriorates quickly. In Eucalyptus maculosa pollen lost all viability during one month storage at room temperature (Boden, 1958), while pollen from Eucalyptus regnans varied from low to high viability after 36 days at room temperature and had no viability after one year's storage at room temperature (Griffin et al., 1982). An example of room temperature storage in M. cajuputi subsp cajuputi, pollen lost almost all viability (3.5\%) during 18 weeks storage at $-3^{\circ} \mathrm{C}$ (Hendrati et al., 2002). On the other hand, Boden (1958) also reported that pollen of E. maculosa stored in a deep-freezer $\left(-16^{\circ} \mathrm{C}\right)$ maintained its germination percentage, although an initial decline occurred in the first month, but it was still $60 \%$ viable after 7 months.

Under the best storage conditions $\left(-18^{\circ} \mathrm{C}\right), 22 \%$ of $M$. alternifolia pollen remained viable after 52 weeks; at room temperature over 52 weeks the result was 10\% (Figure 4). Pollen retained some viability at room temperature after 52 weeks, probably due to being dried using the freeze drying technique. This technique reduced the pollen moisture content to $5.3 \%$, and this low moisture content would have been maintained because pollen was stored in sealed vials and in a desiccator. As hydration is critical for pollen germination, pollen storage is more effective when it is in a partially dehydrated condition (Shivana and Johri, 1985; Barbanas and Kovacs, 1997).

\section{CONCLUSION}

Based on the number of pollen tubes and the seed set observations, the stigma receptivity began to develop from day 1 to day 7 with peak receptivity during day 3 to day 6 after anthesis. The stigma receptivity also coincides with the appearance of secretion in the stigma, occurring from day 3 to day 7 after anthesis. Therefore, the time for pollination period of $M$. alternifolia appears to extend for approximately 7 days after anthesis.

Data for M. alternifolia show that regardless of storage temperature, pollen is still viable after 26 weeks of storage. Results also demonstrated that the lowest temperature $\left(-18^{\circ} \mathrm{C}\right)$ is the best regime for long term storage.

\section{ACKNOWLEDGEMENT}

Thanks to Australian Centre for International Agricultural Research (ACIAR) for the scholarship, to Commonwealth Scientific and Industrial Research Organisation (CSIRO), Forest Biosciences, and the Australian National University (ANU) for the technical supports. I am very grateful to Prof. Peter Kanowski, Dr. John Doran, Mr. Mike Moncur for their invaluable comments and supports. Thanks are also due to Dr. Roger Heady and Dr. Cheng Huang for electron microscopy and fluorescence microscopy assistance, and Dr. Emlyn Williams for statistical supports. 


\section{REFERENCES}

Barbanas, B. and G. Kovacs. 1997. Storage of pollen. In: K.R. Shivana and V.K. Sawney (Eds.). Pollen Biotechnology for Crop Production and Improvement: 293-314. Cambridge, UK, Cambridge University Press. 464p.

Baskorowati, L. 2006. Controlled Pollination Methods for Melaleuca alternifolia (Maiden \& Betche) Cheel. ACIAR Technical Report 63. ACIAR, Canberra. 17p.

Boden, R.W. 1958. Handling and storage of pollen in Eucalyptus breeding. Australian Forestry 22: 73-81.

Cauvin, B. 1984. Eucalyptus hybridization controlee-premiers resultant (Artificial hybridisation of Eucalyptus-preliminary results). In: Annales de recheeches silvicole 1983. Pp. 85-117.

Craig, S., and C.D. Beaton. 1996. A simple cryo-SEM method for delicate plant tissues. Journal of Microscopy 182: 102-105.

Griffin, A.R. and F.C. Hand. 1979. Post-anthesis development of flowers of Eucalyptus regnans $\mathrm{F}$. Muell and the timing of artificial pollination. Australian Forestry Research 9: 9-15.

Griffin, A.R., K.K. Ching, K.W. Johnson, F.C. Hand, and I.P. Burgess. 1982. Processing Eucalyptus pollen for use in controlled pollination. Silvae Genetica 31: 198-203.

Gunn, B.V. 2001. Australian Tree Seed Centre Operations Manual. CSIRO Forestry and Forest Products, Canberra. 158p.

Hendrati, R. L., L. Baskorowati, and N. Kartikawati. 2002. Reproductive biology of Melaleuca cajuputi subsp. cajuputi. In: Rimbawanto, A. and M. Susanto (Eds.). Proceedings of International Seminar on Advances in Genetic Improvement of Tropical Tree Species: 139-143. Centre for Forest Biotechnology and Tree Improvement, Yogyakarta, Indonesia.

Heslop-Harrison, Y. and K.R. Shivanna. 1977. The receptive surface of the angiosperms stigma. Annals of Botany 41: 1233-1258.

Hodgson, L.M. 1976. Some aspects of flowering and reproductive behaviour in Eucalyptus grandis (Hill) Maiden. 1: Flowering, controlled pollination methods, pollination and receptivity. South African Forestry Journal 97: 18-28.

Holmes, G.D. 2000. Interspecific Hybridisation in Clematis L. Master Applied of Science Horticulture Thesis. University of Melbourne, Australia.

Horsley, T.N., S.D. Johnson, and T.K. Stanger. 2007. Optimising storage in vitro germination of Eucalyptus pollen. Australian Journal of Botany 55: 83-89.

Jain, A. and K.R. Shivana. 1989. Loss of viability during storage is associated with changes in membrane phospholipid. Phytochemistry 28: 999-1002. 
Martin, F.W. 1959. Staining and observing pollen tubes in the style by means of fluorescence. Stain Tecnology 34: 125 -128.

O'Brien, S.P. 1996. Timetable of stigmatic receptivity and development and pollen tube growth in Chamelaucium ucinatum. Australian Journal of Botany 44: 649-659.

Oddie, R.L.A. and J.A. McComb. 1998. Stigma receptivity in Eucalyptus camaldulensis Denhnh. Silvae Genetica 47: 142-146.

Owens, J.N., P. Sornsanthapornkul, and S. Tamingcharoen. 1992. Manual: Studying Flowering and Seed Ontogeny in Tropical Forest Trees. ASEAN-Canada Forest Tree Seed Centre Project. Thailand. 134p.

Page, T., G.M. Moore, J. Will, and G.M. Halloran. 2006. Onset and duration of stigma receptivity in Kunzea pomifera (Myrtaceae). Australian Journal of Botany 54: 559-563.

Potts, B.M. and J.B. Marsden-Smedley. 1989. In vitro germination of Eucalyptus pollen: response to variation in boric-acid and sucrose. Australian Journal of Botany 37: 429-441.

Pryor, L.D. 1976. The Biology of Eucalypts. Edward Arnold, London. 82p.

Sanzol, J. and M. Herrero. 2001. Review: The effective pollination period in fruit trees. Scientia Horticulture 90: 1-17.

Savva, M., B.M. Potts, and J.B. Reid. 1988. The breeding system and gene flow in Eucalyptus unigera. In: R.B. Knox, M.B. Sigh, and L. Troini (Eds.). Pollination '88. Plant Cell Biology Research Centre, University of Melbourne, Parkville, Australia. Pp. 176-182.

Sedgley, M. and J. Harbard. 1993. Pollen storage and breeding system in relation to controlled pollination of four species of Acacia (Leguminosae: Mimosaideae). Australian Journal of Botany 41: 601-609.

Sedgley, M. and R.M. Smith. 1989. Pistil receptivity and pollen tube growth in relation to the breeding system of Eucalyptus woodwardii (Symphyomyrtus: Myrtaceae). Annals of Botany 64: 21-31.

Sedgley, M., J. Harbard, and R.M. Smith. 1992. Hybridisation Techniques for Acacias. ACIAR Technical Reports No. 20. ACIAR, Canberra. 11p.

Shivana, K.R. and Johri, B.M., 1985. The Angiosperm Pollen, Structure and Function. Wiley Eastern Limited, New Dehli. 374p.

Tibbits, W.N. 1989. Controlled pollination studies with shinning gum (Eucalyptus nitens (Deane \& Maiden) Maiden). Forestry 62: 111-126.

Van Wyk, G. 1977. Pollen handling, controlled pollination and grafting of Eucalyptus grandis. South African Forestry Journal 101: 47-53. 